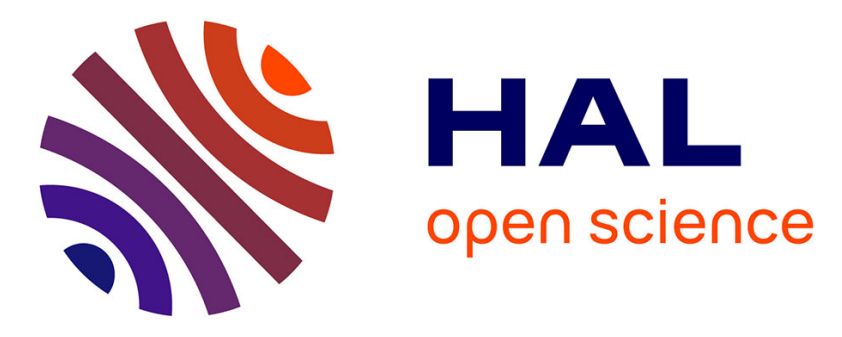

\title{
Mutation in lamin A/C sensitizes the myocardium to exercise-induced mechanical stress but has no effect on skeletal muscles in mouse
}

Marie-Elodie Cattin, Arnaud Ferry, Alban Vignaud, Nathalie Mougenot, Adeline Jacquet, Karim Wahbi, Anne T. Bertrand, Gisèle Bonne

\section{To cite this version:}

Marie-Elodie Cattin, Arnaud Ferry, Alban Vignaud, Nathalie Mougenot, Adeline Jacquet, et al.. Mutation in lamin A/C sensitizes the myocardium to exercise-induced mechanical stress but has no effect on skeletal muscles in mouse. Neuromuscular Disorders, 2016, 10.1016/j.nmd.2016.05.010 . hal-01329664

\section{HAL Id: hal-01329664 https: / hal.sorbonne-universite.fr/hal-01329664}

Submitted on 9 Jun 2016

HAL is a multi-disciplinary open access archive for the deposit and dissemination of scientific research documents, whether they are published or not. The documents may come from teaching and research institutions in France or abroad, or from public or private research centers.
L'archive ouverte pluridisciplinaire HAL, est destinée au dépôt et à la diffusion de documents scientifiques de niveau recherche, publiés ou non, émanant des établissements d'enseignement et de recherche français ou étrangers, des laboratoires publics ou privés. 


\section{Accepted Manuscript}

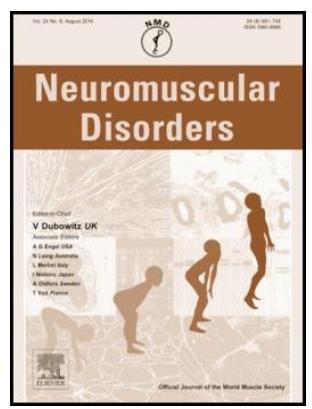

Title: Mutation in lamin A/C sensitizes the myocardium to exercise-induced mechanical stress but has no effect on skeletal muscles in mouse

Author: Marie-Elodie Cattin, Arnaud Ferry, Alban Vignaud, Nathalie

Mougenot, Adeline Jacquet, Karim Wahbi, Anne T. Bertrand, Gisèle Bonne

PII: $\quad$ S0960-8966(16)30186-9

DOI: $\quad$ http://dx.doi.org/doi: 10.1016/j.nmd.2016.05.010

Reference: $\quad$ NMD 3189

To appear in: $\quad$ Neuromuscular Disorders

Received date: $\quad 17-4-2016$

Accepted date: 18-5-2016

Please cite this article as: Marie-Elodie Cattin, Arnaud Ferry, Alban Vignaud, Nathalie

Mougenot, Adeline Jacquet, Karim Wahbi, Anne T. Bertrand, Gisèle Bonne, Mutation in lamin

$\mathrm{A} / \mathrm{C}$ sensitizes the myocardium to exercise-induced mechanical stress but has no effect on skeletal muscles in mouse, Neuromuscular Disorders (2016), http://dx.doi.org/doi:

10.1016/j.nmd.2016.05.010.

This is a PDF file of an unedited manuscript that has been accepted for publication. As a service to our customers we are providing this early version of the manuscript. The manuscript will undergo copyediting, typesetting, and review of the resulting proof before it is published in its final form. Please note that during the production process errors may be discovered which could affect the content, and all legal disclaimers that apply to the journal pertain. 
Mutation in lamin A/C sensitizes the myocardium to exercise-induced mechanical stress but has no effect on skeletal muscles in mouse

Marie-Elodie Cattin ${ }^{1+*}$, Arnaud Ferry ${ }^{1,2}$, Alban Vignaud ${ }^{1, \#}$, Nathalie Mougenot ${ }^{3}$, Adeline Jacquet $^{3}$, Karim Wahbi ${ }^{1,2,4}$, Anne T. Bertrand ${ }^{1}$, Gisèle Bonne ${ }^{1}$.

${ }^{1}$ Sorbonne Universités, UPMC Univ Paris 06, INSERM UMRS_974, CNRS FRE 3617, Center of Research in Myology, F-75013, Paris, France.

${ }^{2}$ Sorbonne Paris Cité, Université Paris Descartes, Paris, F-75006 France

${ }^{3}$ Sorbonne Universités, UPMC Univ Paris 06, INSERM UMS28 Phénotypage du petit animal, Faculté de Médecine Pierre et Marie Curie, F-75013, Paris, France.

${ }^{4}$ AP-HP Groupe Hospitalier Cochin-Broca-Hôtel Dieu, Service de Cardiologie, 75014 Paris, France

+ Current address: University of Ottawa Heart Institute, Ottawa, Ontario, Canada

\# Current address: Généthon, R\&D department, Evry, F-91002, France

* To whom correspondence should be addressed: Marie-Elodie Cattin, University of Ottawa Heart Institute, 40 Ruskin St, Ottawa, Ontario, K1Y 4W7, Canada. Tel.: +1-613-761-4274; Fax: +1-613-761-1597; E-mail: mcattin@ottawaheart.ca. 


\title{
Highlights
}

- The impact of exercise on heart and muscles of $L m n a^{\text {delK32/+ }}$ mice was investigated.

- Strenuous chronic exercise led to earlier onset of the cardiomyopathy in Lmna ${ }^{\text {delK32/+ }}$ mice.

- Skeletal muscle structure and function was not impacted by exercise-induced stress.

\begin{abstract}
LMNA gene encodes lamin $\mathrm{A} / \mathrm{C}$, ubiquitous proteins of the nuclear envelope. They play crucial role in maintaining nuclear shape and stiffness. When mutated, they essentially lead to dilated cardiomyopathy with conduction defects, associated or not with muscular diseases. Excessive mechanical stress sensitivity has been involved in the pathophysiology. We have previously reported the phenotype of $L m n a^{\text {delK32 }}$ mice, reproducing a mutation found in LMNA-related Congenital Muscular Dystrophy patients. Heterozygous Lmna ${ }^{\text {delK32/+ }}$ (Het) mice develop a progressive dilated cardiomyopathy leading to death between 35 and 70 weeks of age. To investigate the sensitivity of the skeletal muscles and myocardium to chronic exercise-induced stress, Het and wild-type (Wt) mice were subjected to strenuous running treadmill exercise for 5 weeks. Before exercise, the cardiac function of Het mice was similar to Wt-littermates. After the exercise-period, Het mice showed cardiac dysfunction and dilation without visible changes in cardiac morphology, molecular remodelling or nuclear structure compared to $\mathrm{Wt}$ exercised and Het sedentary mice. Contrary to myocardium, skeletal muscle ex vivo contractile function remained unaffected in Het exercised mice. In conclusion, the expression of the Lmna ${ }^{\text {delK32 }}$ mutation increased the susceptibility of the myocardium to cardiac stress and led to an earlier onset of the cardiac phenotype in Het mice.
\end{abstract}

Key words: A-type lamin, L-CMD, dilated cardiomyopathy, mechanical stress, chronic exercise 


\section{Introduction}

Lamin A and $\mathrm{C}$ are proteins of the type $\mathrm{V}$ intermediate filament family. They result from alternative splicing of $L M N A$ gene transcript [1]. They assemble in a highly organized structure that forms a meshwork beneath the inner nuclear membrane: the nuclear lamina. The physiological roles of lamin $\mathrm{A} / \mathrm{C}$ are not yet all fully understood but major advances have been made in the past decade, increasing the complexity of these proteins. Their filamentous nature and the regular organization of the meshwork, together with their numerous interactions with many proteins of the nuclear membrane (e.g; Emerin, SUN proteins, nuclear pore complexes among many others) provide structure and stiffness to the nucleus. Therefore, lamin $\mathrm{A} / \mathrm{C}$ plays fundamental role in the nuclear and cellular mechanical resistance. They also largely interact with proteins of the nucleoplasm and with chromatin, influencing all the nuclear functions (DNA replication, RNA transcription, chromatin organization among others), extending their properties to regulation of gene expression and transmission of signaling cascades [2]. By providing physical coupling between the cytoplasm and the nuclear interior, lamins have been shown to integrate external mechanical cues, allowing force transmission from the outside of the cell to adapt gene expression to face changes in cellular environment [3].

To date, more than 500 mutations in $L M N A$ gene have been reported (http://www.umd.be/LMNA/ and G Bonne, R Ben Yaou, personal communications) and lead to a wide spectrum of diseases collectively referred to as laminopathies [4]. These pathologies involve either specific tissues (striated muscles, adipose tissue, peripheral nerves) or several systems (progeroid syndromes) with overlapping phenotypes. Among all LMNA mutations identified in patients, more than $60 \%$ lead to striated muscle-specific diseases [5]. Four striated muscle laminopathies have been described involving different muscles and of different severity: Emery-Dreifuss muscular dystrophy (EDMD) [6], limb girdle muscular 
dystrophy type 1B (LGMD1B) [7], LMNA-related congenital muscular dystrophy (L-CMD) [8] and dilated cardiomyopathy with conduction disease (DCM-CD) [9]. This last entity can be of diverse severity but is a common feature to all laminopathies affecting striated muscles $[10]$.

The mechanisms by which mutations in lamin $\mathrm{A} / \mathrm{C}$, proteins ubiquitously expressed in differentiated cells, lead to tissue-specific diseases remain unclear. Based on their crucial roles in mechanical adaptation and signaling transmission to gene expression, two major nonexclusive hypotheses are now collectively accepted (reviewed in [5] and [11]): (i) the 'structural hypothesis' proposes that one of the most important function of the nuclear lamina would be to maintain the structural integrity of cells, particularly cells subjected to constant mechanical stress (as striated muscles). Lamin dysfunction due to mutation would lead to cellular weakness and/or lack of cellular abilities to properly adapt to the microenvironment, ultimately promoting death and/or inadequate adaptation when cells are subjected to high mechanical stress (reviewed in [3]) (ii) the 'gene regulation hypothesis' proposes that altered patterns of gene expression, due to genome modifications and to improper regulation/transmission of signaling pathways, induced by the expression of mutant lamin, might be the underlying causes of the diseases [12].

We reported the Lmna ${ }^{\text {delK32 }}$ mouse model (deleted for lysine in position 32 of lamin A/C) $[13,14]$, mutation responsible for severe form of EDMD and L-CMD in patients [8, 1518]. The homozygous Lmna ${ }^{\text {delK32/delK32 }}$ mice die at 2 weeks of age due to severe global maturation defects and metabolic disorders [13]. The heterozygous Lmna ${ }^{\text {delK32/+ }}$ mice (referred to as Het mice) were the first Lmna knock-in mice that present a cardiac phenotype at the heterozygous state. They develop a progressive cardiac systolic dysfunction followed by ventricle dilation (DCM) without rhythm or conduction defect, evolving to death between 35 and 70 weeks of age [14]. 
As mentioned above, it has been shown that intact nuclear lamina network is crucial for the maintenance of proper cellular architecture and mechanical stiffness notably in muscular cells. Because the deletion of lysine 32 leads to an important reduction of the protein stability and content in tissue $[13,14]$, we hypothesized that the expression of mutant delK32-lamin A/C would increase the vulnerability of mechanically challenged tissues. In the present study, we investigated the sensitivity of the skeletal muscles and myocardium of Het mice to exercise-induced mechanical stress. To unravel the effect of myocardial stress on the development of the dilated cardiomyopathy observed in Het mice, we studied 17 week-old Het and wild-type (Wt) mice, before the onset of any cardiac dysfunction [14]. Het and Wt mice were subjected to strenuous treadmill protocol ( 5 weeks, 5 days/week, $45 \mathrm{~min} /$ day at speed ranging from 16 to $21 \mathrm{~m} / \mathrm{min}$ ), cardiac and skeletal muscles function and structure were analysed. 


\section{Materials and Methods}

\subsection{Animals and treadmill protocol}

Lmna $^{\text {delK32 }}$ knock-in mice in a C57B1/6_129/SvJ genetic background were generated and genotyped as previously described [5]. Mutant and WT male littermates were studied according to protocols approved by the European legislation (L358-86/609/EEC). The phenotype of Het mice has been reported previously [14]. Forced exercise was performed on a rodent motorized treadmill (Bioseb LE8710M; 0\% incline). Exercise performance of 17 week-old Het and Wt mice was assessed before the 5-week chronic exercise period by an exercise tolerance test. This tolerance test consisted in graded increments of running speed from 7 to $21 \mathrm{~m} / \mathrm{min}$ in 15 minutes after which the speed was kept constant at $21 \mathrm{~m} / \mathrm{min}$ and time to exhaustion was recorded. Exhaustion occurred when mice were unable to maintain the running speed despite electrical stimuli received from a grid at the base of each lane. Mice were then randomly assigned into four groups: Wt sedentary (Wt-S, n=4), Wt exercised (WtE, $n=5$ ), Het sedentary (Het-S, n=9) and Het exercised (Het-E, n=9). For strenuous chronic exercise training, mice ran at speed ranging from 16 to $21 \mathrm{~m} / \mathrm{min}$ at $0 \%$ incline for $45 \mathrm{~min}, 5$ sessions/week for 5 weeks (Fig. 1A). The protocol included 3 days of acclimatization and 15 min of warm-up per session.

All the analyses (in vivo, ex vivo and in vitro) have been performed blindly.

\subsection{Cardiac function measurement}

Transthoracic echocardiography was performed at room temperature on sedated mice (0.5\% isofluorane) using an echocardiography-Doppler (General Electric Medical systems Co, Vivid 7 Dimension/Vivid 7 PRO) with a probe emitting ultrasounds with 9-14 $\mathrm{MHz}$ frequency, as described in [14]. 


\subsection{Muscle contractile properties}

The isometric contractile properties of soleus muscles were studied in vitro as previously described [19]. Briefly, Soleus muscles were soaked in an oxygenated Krebs solution (95\% O2 and 5\% CO2) containing $58.5 \mathrm{mM} \mathrm{NaCl}, 24 \mathrm{mM} \mathrm{NaHCO} 3,5.4 \mathrm{mM} \mathrm{KCl}$, $1.2 \mathrm{mM} \mathrm{KH} 2 \mathrm{PO} 4,1.8 \mathrm{mM} \mathrm{CaCl} 2,1 \mathrm{mM} \mathrm{MgSO} 4$, and $10 \mathrm{mM}$ glucose, $\mathrm{pH} \mathrm{7.4}$, and maintained at a temperature of $22^{\circ} \mathrm{C}$. One of the muscle tendons was attached to a lever arm of a servomotor system (300B Dual-Mode Lever; Aurora Scientific). After equilibration (30 min), electrical stimulation was delivered through electrodes running parallel to the muscle. 1ms pulses were generated by a high power stimulator (701B; Aurora Scientific). The maximal force $\left(\mathrm{P}_{0}\right)$ was measured at $\mathrm{L}_{0}$ (optimal muscle length for maximal force production) during isometric contractions in response to electrical stimulation (frequency of 50-125 Hz; train of stimulation of $1500 \mathrm{~ms}$ ). Fatigue resistance was determined after a 5-min rest period. Muscles were stimulated at $75 \mathrm{~Hz}$ during $500 \mathrm{~ms}$ every $1.6 \mathrm{~s}$ for $3 \mathrm{~min}$. The time for initial force to fall by $20 \%$ was determined. Soleus muscles were weighted and $\mathrm{sP}_{0}$ (specific maximal force) was calculated by dividing $\mathrm{P}_{0}$ by the estimated cross-section area (CSA) of the muscle. Muscle cross-sectional area was calculated using the following equation: CSA $=$ (muscle mass, in gram) $/\left[1.06 \mathrm{~g} / \mathrm{cm}^{3} \times\right.$ (optimal fiber length, in $\left.\left.\mathrm{cm}\right)\right] .1 .06 \mathrm{~g} / \mathrm{cm}^{3}$ is the muscle density. The optimal fiber length is calculated as $0.70 \times \mathrm{L}_{\mathrm{o}} .0 .70$ represents the ratio of the optimal fiber length to the $\mathrm{L}_{\mathrm{o}}$ of the soleus muscle.

\subsection{Histology and immunochemical analysis}

Fresh heart and Plantaris muscle samples were snap frozen in liquid-nitrogen-cooled isopentane (VWR International, Fontenay-sous-Bois, France), and stored at $-80^{\circ} \mathrm{C}$ until further processing. Three animals were analysed in each group. Frozen sections $(8 \mu \mathrm{m})$ of transversal cardiac and Plantaris muscle were stained with Sirius red for fibrosis visualization 
and Hematein/eosin, respectively. Sections were analysed by light microscopy. For immunohistochemical analysis, tissue sections were fixed for $10 \mathrm{~min}$ in $100 \%$ acetone at $20^{\circ} \mathrm{C}$ (sections were not fixed before vinculin staining) and incubated for $30 \mathrm{~min}$ with blocking solution (5\% bovine serum albumin IgG-free in PBS) at room temperature. Primary mouse IgG1 anti-vinculin monoclonal Ab (1:250, Sigma Aldrich) and goat anti-lamin B1 polyclonal $\mathrm{Ab}(1: 100$, Santa Cruz) were diluted in blocking solution and sections were incubated for $1 \mathrm{~h} 30$ at room temperature. Sections were washed three times with PBS and incubated with secondary Ab (1:500, Alexa fluor 568-conjugated donkey anti-goat IgG and Alexa fluor 488-conjugated goat anti-mouse $\mathrm{IgG1}$ ) for $30 \mathrm{~min}$ at room temperature. Cardiac sections were mounted with mounting medium (Vectashield) with 40,6-diamidino-2phenylindole dihydrochloride (DAPI) and images were acquired with a Carl Zeiss Axiophot1 fluorescence microscope. Collagen proportion, cardiomyocytes cross-section areas and nuclei length were measured using NIS Software. Proportion of lengthened nuclei was evaluated by counting all nuclei with length over $20 \mu \mathrm{m}\left(95^{\text {th }}\right.$ percentile of Wt Sedentary mice nuclei length distribution).

\section{5. $m R N A$ analysis}

Heart were harvested and rapidly frozen in liquid-nitrogen. Total RNA was extracted using RNeasy fibrous tissue mini kit (Qiagen) and qPCR was performed as described in [14]. The sequences of oligonucleotides used for qRT-PCR analysis are listed in the Supplemental Table 1. Five animals in Wt-E, Het-E, Het-S groups and four animals in Wt-S group were analysed.

\subsection{Statistical analysis}

Differences between groups were assessed with Sigmastat software using two-way ANOVA followed by Holm-Sidak test for multiple comparisons for normally distributed data, 
and two-way ANOVA on Ranks for the data that were not normally distributed. Probability values of $\mathrm{p}<0.05$ were considered statistically significant. 


\section{Results}

\subsection{Exercise ability}

Prior to the 5-week forced-exercise period, the overall ability of Wt and Het mice to exercise was assessed using an exercise tolerance test. Wt and Het mice were able to sustain exercise for an average time of 55 and $53 \mathrm{~min}$, respectively (Fig. 1B). This test indicated that the running ability and endurance was similar in Het and Wt mice, confirming that Het mice did not show major muscular, cardiac or metabolic defects at that age, as described previously [14]. Mice were then randomly assigned into four groups: Wt sedentary (Wt-S, n=4), Wt exercised (Wt-E, n=5), Het sedentary (Het-S, n=9), Het exercised (Het-E, n=9); Wt and Het exercised mice were subjected to the treadmill running protocol. The average running time per session was similar in Het-E and Wt-E throughout the 5-week period (Fig. 1C).

\subsection{Survival during the 5 weeks study}

Over the 5-week period of the study, two Het mice died: one sedentary (Het-S) and one exercised (Het-E) Het mice. The Het-E mouse died at day 37, after the 5-week exercise period was completed (Fig. 1A). Therefore, the exercise training did not increase the mortality of Het mice in this study.

\subsection{Muscular function}

The Het mice do not show skeletal muscle dysfunction or histological abnormalities in sedentary conditions [14]. After the 5-week exercise period, we assessed the ex vivo contractile properties of the Soleus muscle (slow-twitch muscle) and the histological features of the Plantaris muscle (fast-twitch muscle), two muscles recruited during exercise. Soleus muscle did not show any contractile dysfunction or gross morphological abnormalities in HetE mice (Table 1; Two-way ANOVA, p>0.05 for all parameters). In addition, the histological 
structure of the Plantaris muscle was preserved in Het-E mice compared to Wt and Het-S (Fig. 2). These results indicated that exercise-induced stress did not affect skeletal muscle structure and function in this study.

\subsection{Cardiac function}

All echocardiographic parameters were similar in Het and Wt mice before the 5-week exercise period, as expected at this age (Table 2, [14]). All cardiac parameters of Wt mice were identical at baseline and after the 5-week period of the study without any difference between sedentary and exercised mice. After the 5-week exercise period ( 22 weeks of age), the fractional shortening was decreased in Het mice (exercised and sedentary) compared to Wt mice (FS: $34 \pm 6.1 \%$ vs $40.6 \pm 4.7 \%$, p=0.008), indicating a cardiac contractile dysfunction in Het mice. This result was in accordance with the natural time course of the DCM progression in Het mice [14]. The cardiac wall thickness in diastole (IVSd) was similar in all groups, indicating no sign of cardiac hypertrophy in exercised mice.

The exercise-induced stress resulted in a trend toward decreased cardiac function in Het-E mice compared to Het-S mice (FS: $31.7 \pm 6.21 \%$ vs $36.3 \pm 5.5 \%$, respectively, $\mathrm{p}=0.091$ ) and significant increase in ventricular dilation in both diastole and systole in Het-E mice when compared to Het-S mice (LVEDD: $\mathrm{p}<0.01$ vs Het-S; LVESD: $\mathrm{p}<0.05$ vs Het-S; Table 2 and Figure 3A-B). The Het-E mice also demonstrated significant depression in cardiac function when compared to Wt-E mice (lower fractional shortening and thinner interventricular septum in systole (IVSs)), and ventricular dilation $(\mathrm{p}<0.01$ and $\mathrm{p}<0.05$, respectively; Table 2 and Figure 3A-B).

In our first description of the Het mice [14], we reported that the ventricular dilation was observed after 30 weeks of age in Het male mice and, importantly, the decrease in FS always occurred before the ventricular dilation. In the present study, the results indicated that exercise-induced stress accelerated the onset of the cardiomyopathy in the Het mice (dilation 
and decreased FS), suggesting that the expression of the mutant delK32-lamin A/C weakened the myocardium.

\subsection{Cardiac morphology}

Despite contractile dysfunction and relative dilation of the left ventricle, heart weight to tibia length ratio was similar in Het-S when compared to the other groups (Fig. 3C), indicating no cardiac hypertrophy. Myocardial structure was further examined by immunohistology. The distribution of cardiomyocyte cross-section area (CSA) was similar in all groups, despite a trend toward a higher proportion of smaller CSA in Het mice (Fig. 3D-E). We investigated whether myocardial matrix remodeling could explain contractile dysfunction observed in Het-S mice. Interstitial fibrosis was quantified using Sirius red staining of collagen (Fig. 3F-G) and the expression of Transforming Growth Factor $\beta$ genes (Tgfbl and $T g f b 2$ ), increased during matrix remodeling, was measured by qRT-PCR (Fig. 3H-I). Both parameters were not statistically different between groups.

\subsection{Cardiomyonuclei morphology}

Modifications of nuclear morphology are frequently associated with A-type lamins deficiency. Particularly, fragile and elongated nuclei have been reported in different cell types $[13,20-22]$. We previously described such elongated nuclei in the myocardium of Het mice [14]. We measured nuclei length in the heart of Het and Wt mice exercised or sedentary (Fig. 4). The results indicated that, despite a similar overall distribution of nuclear length in Het and Wt mice (Fig. 4B), both Het-S and Het-E mice showed a higher proportion of elongated nuclei (length $>20 \mu \mathrm{m}$, Fig. 4A and C). However, exercise had no additional effect on this parameter in Wt or in Het mice.

\subsection{Cardiac molecular remodelling}


Expression levels of molecular markers specific of cardiac remodeling, i.e., Nppa, Nppb, Myh6 and Myh7 were assessed. In addition, expression of mechanosensitive early genes Egrl and Iexl, previously used as markers for mechanical defective sensing or resistance in Lamin mutant mice [23], was measured. Both Egrl and Iexl showed similar expression levels in all groups (Fig. 5A-B), even if Egrl expression tended to be higher in the heart of Het-E mice. Ventricular expression of natriuretic peptides reflects ventricular stretch and remodeling processes. They are expressed at low level in normal conditions but increase under pathological stress conditions. Here, the expression of both Nppa and Nppb was not statistically different between groups (Fig. 5C-D). Beta-myosin heavy chain (Myh7) was highly increased in Het mice, without effect of exercise. Whereas, the alpha-myosin heavy chain expression (Myh6) was similar in all groups (Fig. 5E-F). These results indicated that contractile proteins (myosin heavy chains) expression was altered in Het mice, accounting for the early stage of cardiac dysfunction. However, despite the myocardial sensitivity to exercise-induced stress, there was no significant effect of exercise on cardiac remodeling markers expression. 


\section{Discussion}

The Het mice develop a progressive cardiac dysfunction followed by ventricle dilation (DCM) without rhythm or conduction defect, evolving to death between 35 and 70 weeks of age [14]. Here we investigated the impact of chronic exercise-induced mechanical stress on cardiac and skeletal muscle function of Het mice. The major findings of this study are: (i) strenuous exercise did not increase the mortality of Het mice but (ii) led to an anticipation of the onset of the cardiac phenotype as shown by the earlier left ventricle dilation; (iii) importantly, skeletal muscle structure and function remained unaltered under exerciseinduced stress.

A large variety of imposed exercise protocols can be found in the literature to challenge cardiac and skeletal muscle function in mouse. Depending on the nature of the exercise (forced exercise on treadmill, voluntary wheel or swimming), the intensity and the frequency, different effects have been observed in terms of cardiac response to stress. Some authors reported moderate cardiac hypertrophy; others showed that heart size and morphology remained unaffected [24-27]. Because of the lack of consensus regarding strenuous exercise protocols, we designed a protocol relatively similar to the one applied to heterozygous Lmna ${ }^{\Delta 8-11}$ mice [28]. These mice expressed a truncated form of lamin A/C at low level [29, 30]. They develop early cardiac rhythm and conduction abnormalities and a dilated cardiomyopathy $[28,29]$ of milder severity compared with the DCM observed in Het mice [14]. Chandar and colleagues showed previously that regular moderate exercise had beneficial effect on the DCM in Lmna $a^{\Delta 8-11}$ mice, slowing down the progression of the contractile dysfunction and reducing the ventricle dilation [28]. They also evaluated the impact of exercise intensity on those mice and showed that the benefit of exercise was lost under strenuous exercise training. However, mechanical stress induced by this intense exercise did not worsen the DCM phenotype of Lmna $a^{\Delta 8-11}$ mice. In $L m n a^{\text {delK32/+ }}$ mice, strenuous exercise 
had a significant impact on the cardiac phenotype. We showed that the expression of the $L m n a^{\text {delK32 }}$ mutation increased the susceptibility of the myocardium to cardiac stress: exerciseinduced stress modified the time course of DCM (dilation occurring earlier in Het-E when compared to Het-S mice) and led to a more severe cardiac phenotype. This result is in accordance with our previous report showing that mutant $L m n a^{\text {delK32 }}$ is highly deleterious for the heart [14]. Function and ventricle dimensions were altered before myocardial structural abnormalities could be seen, suggesting fine intrinsic alterations under mechanical stress in Het hearts. Further analyses are needed to delineate the mechanisms responsible for this anticipation of the onset of DCM in Het mice.

Many studies have shown that lamin A/C expression level is cell-type dependent and associates with stiffness of the nucleus and of the tissue [31]. Particularly, cells isolated from $L m n a^{\Delta 8-11}$ mice have altered nuclear shape and chromatin organization, and show increased deformability and reduced viability in response to biaxial strain in vitro [32]. In vivo, lamin A/C deficiency leads to impaired response to pressure-overload induced mechanical stress, linked to the inability of cardiomyocytes to properly activate mechanosensing pathways [33, 34]. We recently reported that human myoblasts from patients harbouring $L M N A^{\mathrm{delK} 32 /+}$ mutation demonstrated an inability to properly sense and mediate mechanical cues coming from their microenvironment [35]. This feature was associated with altered shape and elongated nuclei, as observed in Het hearts. Therefore, cardiac dilation observed in Het-E mice might result from inadequate sensing and/or remodelling to cope with increased myocardial stress. We previously showed that delK32-lamin was unstable and subjected to constant degradation in the cardiac and skeletal muscle tissue $[13,14]$, leading to a reduction of $50 \%$ of lamin $\mathrm{A} / \mathrm{C}$ protein level in Het mice. Level of lamin A protein correlates with stiffness of the tissue, stiffer tissues which sustain high stress and mechanical tension expressing higher amount of lamin A protein [36]. Tightly regulated lamin A level contributes 
to specific tissue response to their mechanical environment and allows to maintain tissue homeostasis. The decreased amount of lamin A/C, together with the negative impact of mutant delK32 lamin in Het hearts [14], is therefore likely to affect myocardial resistance to exercise-induced mechanical stress and could explain the earlier onset of the DCM observed in this study.

Exercise training is approved as therapeutic intervention for stable NYHA class I-III heart failure patients. It has been shown to reduce mortality and hospitalization in patients suffering from mild to moderate heart failure [37]. The beneficial effects of exercise are largely documented and include improvement of endothelial dysfunction, reduction of neurohormonal hyperactivation, anti-inflammatory effects and improvement of general hemodynamics parameters in patients with heart failure [38, 39]. However, intensive exercise could also have a negative impact on the heart, especially in a cardiomyopathic context. For instance, competitive sport activities must be discouraged for patients suffering from or diagnosed with genetic conditions associated with hypertrophic cardiomyopathy or DCM, in which intensive exercise increases the risk of sudden death due to ventricular arrhythmia. For these patients only recreational and/or low-moderate dynamic sports are recommended [40, 41]. Contraindications have also been raised for patients with complex ventricular arrhythmia at rest or appearing with exertion [38], conditions associated with $L M N A$-related DCM-CD [10]. In laminopathies, the effect of exercise on cardiac function has not been studied extensively. In a study evaluating the long-term outcome and risk stratification in patients with cardiolaminopathies, Pasotti and colleagues identified an increased risk of major cardiac events (e.g. sudden cardiac death) in LMNA-positive subjects [42]. They concluded that high dynamic competitive sports should be discouraged for these patients. We previously reported that the Het mice represent a valuable model for the study of Lmna-related DCM [14]. Here we show that exercise-induced stress has a negative effect on the onset of this cardiac 
phenotype, reinforcing the idea that $L M N A$-related DCM constitutes a non-common subset of DCM and heart failure. Therefore the present study underlines that, even if considered beneficial for cardiac management of heart failure, exercise might be recommended with caution in LMNA-related DCM patients. In addition, the effect of stress upon myocardial function appears to be mutation-dependent, as $L m n a^{\Delta 8-11 /+}$ and $L m n a^{\text {delK32/+ }}$ mice were differentially affected by exercise-induced stress.

Importantly, in contrast to myocardial susceptibility, exercise-induced mechanical stress had no effect on skeletal muscle in Het mice in this study, confirming that delK32 lamin A/C affects differently cardiomyocytes and muscle cells [13, 14, 35]. 


\section{Acknowledgements}

We thank Maud Beuvin for technical assistance with the histology and Anaïs Lagrange for her assistance in conducting the exercise protocol. This work was financially supported by the Institut National de la Santé et de la Recherche Médicale; the Sorbonne UniversitésUniversité Pierre et Marie Curie Paris 06, the Centre National de la Recherche Scientifique and Association Française contre les Myopathies (AFM).

\section{Disclosures}

None declared

\section{References}

[1] Lin F, Worman HJ. Structural organization of the human gene encoding nuclear lamin A and nuclear lamin C. J Biol Chem 1993;268:16321-6.

[2] Choi JC, Worman HJ. Nuclear envelope regulation of signaling cascades. Adv Exp Med Biol 2014;773:187-206.

[3] Fedorchak GR, Kaminski A, Lammerding J. Cellular mechanosensing: Getting to the nucleus of it all. Prog Biophys Mol Biol 2014;115:76-92.

[4] Worman HJ, Bonne G. "Laminopathies": a wide spectrum of human diseases. Exp Cell Res 2007;313:2121-33.

[5] Bertrand AT, Chikhaoui K, Ben Yaou RB, Bonne G. Clinical and genetic heterogeneity in laminopathies. Biochem Soc Trans 2011;39:1687-92.

[6] Bonne G, Di Barletta MR, Varnous S, et al. Mutations in the gene encoding lamin A/C cause autosomal dominant Emery-Dreifuss muscular dystrophy. Nat Genet 1999;21:285-8.

[7] Muchir A, Bonne G, van der Kooi AJ, et al. Identification of mutations in the gene encoding lamins $\mathrm{A} / \mathrm{C}$ in autosomal dominant limb girdle muscular dystrophy with atrioventricular conduction disturbances (LGMD1B). Hum Mol Genet 2000;9:1453-9.

[8] Quijano-Roy S, Mbieleu B, Bonnemann CG, et al. De novo LMNA mutations cause a new form of congenital muscular dystrophy. Ann Neurol 2008;64:177-86.

[9] Fatkin D, MacRae C, Sasaki T, et al. Missense mutations in the rod domain of the lamin A/C gene as causes of dilated cardiomyopathy and conduction-system disease. N Engl J Med 1999;341:1715-24.

[10] Cattin ME, Muchir A, Bonne G. 'State-of-the-heart' of cardiac laminopathies. Curr Opin Cardiol 2013;28:297-304.

[11] Azibani F, Muchir A, Vignier N, Bonne G, Bertrand AT. Striated muscle laminopathies. Semin Cell Dev Biol 2014;29:107-15.

[12] Kind J, van Steensel B. Genome-nuclear lamina interactions and gene regulation. Curr Opin Cell Biol 2010;22:320-5. 
[13] Bertrand AT, Renou L, Papadopoulos A, et al. DelK32-lamin A/C has abnormal location and induces incomplete tissue maturation and severe metabolic defects leading to premature death. Hum Mol Genet 2012;21:1037-48.

[14] Cattin ME, Bertrand AT, Schlossarek S, et al. Heterozygous LmnadelK32 mice develop dilated cardiomyopathy through a combined pathomechanism of haploinsufficiency and peptide toxicity. Hum Mol Genet 2013;22:3152-64.

[15] D'Amico A, Haliloglu G, Richard P, et al. Two patients with 'Dropped head syndrome' due to mutations in LMNA or SEPN1 genes. Neuromuscul Disord 2005;15:521-4.

[16] Muchir A, Medioni J, Laluc M, et al. Nuclear envelope alterations in fibroblasts from patients with muscular dystrophy, cardiomyopathy, and partial lipodystrophy carrying lamin A/C gene mutations. Muscle Nerve 2004;30:444-50.

[17] Tan D, Yang H, Yuan Y, et al. Phenotype-Genotype Analysis of Chinese Patients with Early-Onset LMNA-Related Muscular Dystrophy. PLoS One 2015;10:e0129699.

[18] Vytopil M, Ricci E, Dello Russo A, et al. Frequent low penetrance mutations in the Lamin A/C gene, causing Emery Dreifuss muscular dystrophy. Neuromuscul Disord 2002;12:958-63.

[19] Agbulut O, Vignaud A, Hourde C, et al. Slow myosin heavy chain expression in the absence of muscle activity. Am J Physiol Cell Physiol 2009;296:C205-14.

[20] Lammerding J, Schulze PC, Takahashi T, et al. Lamin A/C deficiency causes defective nuclear mechanics and mechanotransduction. J Clin Invest 2004;113:370-8.

[21] Nikolova V, Leimena C, McMahon AC, et al. Defects in nuclear structure and function promote dilated cardiomyopathy in lamin A/C-deficient mice. J Clin Invest 2004;113:357-69.

[22] Arimura T, Helbling-Leclerc A, Massart C, et al. Mouse model carrying H222P-Lmna mutation develops muscular dystrophy and dilated cardiomyopathy similar to human striated muscle laminopathies. Hum Mol Genet 2005;14:155-69.

[23] Muchir A, Pavlidis P, Decostre V, et al. Activation of MAPK pathways links LMNA mutations to cardiomyopathy in Emery-Dreifuss muscular dystrophy. J Clin Invest 2007;117:1282-93.

[24] Ericsson M, Andersson KB, Amundsen BH, et al. High-intensity exercise training in mice with cardiomyocyte-specific disruption of Serca2. J Appl Physiol 2010;108:1311-20.

[25] Kemi OJ, Ceci M, Wisloff U, et al. Activation or inactivation of cardiac Akt/mTOR signaling diverges physiological from pathological hypertrophy. J Cell Physiol 2008;214:316-21.

[26] Kemi OJ, Loennechen JP, Wisloff U, Ellingsen O. Intensity-controlled treadmill running in mice: cardiac and skeletal muscle hypertrophy. J Appl Physiol 2002;93:1301-9.

[27] Nakamura A, Yoshida K, Takeda S, Dohi N, Ikeda S. Progression of dystrophic features and activation of mitogen-activated protein kinases and calcineurin by physical exercise, in hearts of mdx mice. FEBS Lett 2002;520:18-24.

[28] Chandar S, Yeo LS, Leimena C, et al. Effects of mechanical stress and carvedilol in lamin A/C-deficient dilated cardiomyopathy. Circ Res 2010;106:573-82.

[29] Wolf CM, Wang L, Alcalai R, et al. Lamin A/C haploinsufficiency causes dilated cardiomyopathy and apoptosis-triggered cardiac conduction system disease. J Mol Cell Cardiol 2008;44:293-303.

[30] Jahn D, Schramm S, Schnolzer M, et al. A truncated lamin A in the Lmna -/- mouse line: implications for the understanding of laminopathies. Nucleus 2012;3:463-74.

[31] Swift J, Discher DE. The nuclear lamina is mechano-responsive to ECM elasticity in mature tissue. J Cell Sci 2014;127:3005-15. 
[32] Lammerding J, Hsiao J, Schulze PC, Kozlov S, Stewart CL, Lee RT. Abnormal nuclear shape and impaired mechanotransduction in emerin-deficient cells. J Cell Biol 2005;170:781-91.

[33] Cupesi M, Yoshioka J, Gannon J, Kudinova A, Stewart CL, Lammerding J. Attenuated hypertrophic response to pressure overload in a lamin $\mathrm{A} / \mathrm{C}$ haploinsufficiency mouse. J Mol Cell Cardiol 2010;48:1290-7.

[34] Ho CY, Jaalouk DE, Vartiainen MK, Lammerding J. Lamin A/C and emerin regulate MKL1-SRF activity by modulating actin dynamics. Nature 2013;497:507-11.

[35] Bertrand AT, Ziaei S, Ehret C, et al. Cellular microenvironments reveal defective mechanosensing responses and elevated YAP signaling in LMNA-mutated muscle precursors. J Cell Sci 2014;127:2873-84.

[36] Swift J, Ivanovska IL, Buxboim A, et al. Nuclear lamin-A scales with tissue stiffness and enhances matrix-directed differentiation. Science 2013;341:1240104.

[37] O'Connor CM, Whellan DJ, Lee KL, et al. Efficacy and safety of exercise training in patients with chronic heart failure: HF-ACTION randomized controlled trial. Jama 2009;301:1439-50.

[38] Piepoli MF, Conraads V, Corra U, et al. Exercise training in heart failure: from theory to practice. A consensus document of the Heart Failure Association and the European Association for Cardiovascular Prevention and Rehabilitation. Eur J Heart Fail 2011;13:347-57.

[39] Piepoli MF. Exercise training in chronic heart failure: mechanisms and therapies. Neth Heart J 2013;21:85-90.

[40] Maron BJ, Chaitman BR, Ackerman MJ, et al. Recommendations for physical activity and recreational sports participation for young patients with genetic cardiovascular diseases. Circulation 2004;109:2807-16.

[41] Pelliccia A, Fagard R, Bjornstad HH, et al. Recommendations for competitive sports participation in athletes with cardiovascular disease: a consensus document from the Study Group of Sports Cardiology of the Working Group of Cardiac Rehabilitation and Exercise Physiology and the Working Group of Myocardial and Pericardial Diseases of the European Society of Cardiology. European heart journal 2005;26:1422-45.

[42] Pasotti M, Klersy C, Pilotto A, et al. Long-term outcome and risk stratification in dilated cardiolaminopathies. Journal of the American College of Cardiology 2008;52:1250-60. 


\section{Figures Legends}

Figure 1. Schematic representation of the protocol and running ability of Wt and Het mice. (A) After 3 days acclimatization, cardiac function was measured using echocardiography. Exercise tolerance test was performed and mice underwent the 5-week exercise period. After $24 \mathrm{~h}$ rest, the cardiac function was assessed using echocardiography. After $48 \mathrm{~h}$ recovery post-echocardiography, mice were euthanized; tissues collected and skeletal muscle function (Soleus) was assessed ex vivo. (B) Exercise tolerance test performed before 5-week exercise period ( $\mathrm{n}=9 \mathrm{Wt}$ and $18 \mathrm{Het}$ ). Mean \pm SEM. (C) Running time at each session of exercise period $(n=5 \mathrm{Wt}$ and 9 Het). Mean \pm SEM.

Figure 2. Skeletal muscle histology of Wt and Het sedentary and exercised mice. Plantaris sections stained with Haematin/eosin. Scale $=50 \mu \mathrm{m}$.

Figure 3. Cardiac function and morphology of Wt and Het sedentary and exercised mice after the 5-week exercise period. (A) Fractional shortening (FS), $* * p<0.01$ compared to $\mathrm{Wt}$ exercised mice. Mean \pm SEM. (B) Left ventricular diameter in diastole, \#\#p<0.01 compared to Het sedentary mice. Mean \pm SEM. (C) Heart weight $(\mathrm{HW})$ to tibia length (TL) ratio in sedentary ( $\mathrm{n}=4 \mathrm{Wt}$ and 8 Het) and exercised mice ( $\mathrm{n}=5 \mathrm{Wt}$ and 8 Het). Mean \pm SEM. (D) Heart sections stained with anti-vinculin antibody, labelling cardiomyocytes membranes (green). Sed $=$ sedentary mice $;$ Ex $=$ Exercised mice. Nuclei are counterstained with DAPI (blue). Scale $=50 \mu \mathrm{m}$. (E) Distribution of cardiomyocytes cross-section areas $(\mathrm{n}=1124 \pm 302$ cardiomyocytes measured per animal). (F) Heart sections stained with Sirius Red showing collagen (red). Scale $=100 \mu \mathrm{m}$. (G) Quantification of collagen staining normalized to total area. Mean \pm SEM. (H-I) mRNA level of Transforming Growth Factor beta $1(\mathrm{H})$ and beta 2 (I) genes. Mean \pm SEM. 
Figure 4. Cardiac nuclei morphology of Wt and Het sedentary and exercised mice. (A) Heart sections stained with anti-lamin B1 antibody, labelling nuclear membrane. Sed = Sedentary mice; $E x=$ Exercised mice. Scale $=50 \mu \mathrm{m}$. (B) Distribution of nuclei length $(\mathrm{n}=272$ \pm 89 nuclei measured per animal). (C) Proportion of elongated nuclei (length $>20 \mu \mathrm{m}$ ). Mean \pm SEM.

Figure 5. Expression of cardiac remodeling markers. (A-B) mRNA level of "mechanosensitive" genes. A, Early growth response 1 (Egr1); B, Immediate early gene response X-1 (Iex1). (C-D) mRNA level of natriuretic peptides genes. C, Atrial natriuretic peptide precursor (Nppa); D, Brain natriuretic peptide precursor (Nppb). (E-F) mRNA level of myosin heavy chain genes. E, alpha-isoform (Myh6); F, beta-isoform (Myh7). ${ }^{*} \mathrm{p}<0.05$ vs training-matched Wt. Mean \pm SEM. 
Table 1. Ex vivo Soleus muscle contractile properties of Wt and Het mice after the 5week exercise protocol. (number of animals). $\mathrm{L}_{0}$ : optimal muscle length; $\mathrm{sP}_{0}$ : specific maximal force. Mean \pm SEM. Two-way ANOVA, $p>0.05$ for all comparisons.

\begin{tabular}{|c|c|c|c|c|}
\hline & \multicolumn{2}{|c|}{ Sedentary } & \multicolumn{2}{|c|}{ Exercised } \\
\hline & Wt (4) & Het (8) & Wt (5) & Het (8) \\
\hline Muscle weight (mg) & $13.6 \pm 0.6$ & $12.8 \pm 0.5$ & $13.2 \pm 1.0$ & $12.8 \pm 0.5$ \\
\hline $\mathrm{L}_{0}(\mathrm{~mm})$ & $13.0 \pm 0.0$ & $12.9 \pm 0.2$ & $12.9 \pm 0.1$ & $13.3 \pm 0.04$ \\
\hline $\mathrm{sP}_{0}\left(\mathrm{mN} / \mathrm{mm}^{2}\right)$ & $176.6 \pm 7.1$ & $167.1 \pm 10.4$ & $148.4 \pm 16.6$ & $184.2 \pm 7.5$ \\
\hline Fatigue (sec) & $35.9 \pm 1.9$ & $32.8 \pm 1.6$ & $33.2 \pm 3.3$ & $31.8 \pm 2.2$ \\
\hline
\end{tabular}


Table 2. Echocardiographic parameters of Wt and Het male mice before (17 weeks of age) and after 5 weeks of exercise protocol ( 22 weeks of age). (number of animals). BW: body weight, IVSd: Interventricular septum thickness in diastole, PWd: Posterior wall thickness in diastole, LVEDD: Left ventricular end-diastolic diameter, IVSs: Interventricular septum thickness in systole, PWs: Posterior wall thickness in systole, LVESD: Left ventricular end-systolic diameter, LVM: Left ventricular mass, FS: Fractional shortening, HR: Heart rate. ${ }^{*} \mathrm{p}<0.05,{ }^{*} \mathrm{p}<0.01$ compared to Wt exercised mice, $\# \mathrm{p}<0.05, \# \# \mathrm{p}<0.01$ compared to Het sedentary mice. ANOVA, Holm-Sidak test. Mean \pm SEM.

\begin{tabular}{|c|c|c|c|c|c|c|}
\hline & \multirow{2}{*}{\multicolumn{2}{|c|}{ Before exercise }} & \multicolumn{4}{|c|}{ After the 5-week period } \\
\hline & & & \multicolumn{2}{|c|}{ Sedentary } & \multicolumn{2}{|c|}{ Exercised } \\
\hline & Wt (9) & Het (18) & Wt (4) & Het (8) & Wt (5) & Het (9) \\
\hline BW (g) & $29.7 \pm 0.53$ & $30.1 \pm 0.75$ & $33.2 \pm 1.55$ & $31.9 \pm 1.10$ & $29.8 \pm 1.16$ & $29.9 \pm 0.57$ \\
\hline HR (bpm) & $503 \pm 14$ & $475 \pm 11$ & $540 \pm 10$ & $539 \pm 13$ & $517 \pm 10$ & $515 \pm 14$ \\
\hline \multicolumn{7}{|l|}{ Diastole } \\
\hline IVS (mm) & $0.66 \pm 0.02$ & $0.63 \pm 0.02$ & $0.65 \pm 0.03$ & $0.60 \pm 0.02$ & $0.62 \pm 0.02$ & $0.60 \pm 0.02$ \\
\hline PW (mm) & $0.83 \pm 0.03$ & $0.81 \pm 0.02$ & $0.83 \pm 0.05$ & $0.80 \pm 0.04$ & $0.78 \pm 0.02$ & $0.73 \pm 0.02$ \\
\hline $\operatorname{LVD}(\mathrm{mm})$ & $4.00 \pm 0.12$ & $4.11 \pm 0.07$ & $4.00 \pm 0.14$ & $4.00 \pm 0.05$ & $4.10 \pm 0.12$ & $4.30 \pm 0.07 \# \#$ \\
\hline \multicolumn{7}{|l|}{ Systole } \\
\hline IVS (mm) & $1.23 \pm 0.04$ & $1.17 \pm 0.04$ & $1.20 \pm 0.06$ & $1.08 \pm 0.04$ & $1.16 \pm 0.05$ & $1.01 \pm 0.04 *$ \\
\hline PW (mm) & $1.24 \pm 0.05$ & $1.19 \pm 0.04$ & $1.33 \pm 0.09$ & $1.23 \pm 0.05$ & $1.18 \pm 0.05$ & $1.11 \pm 0.04$ \\
\hline $\mathrm{LVD}(\mathrm{mm})$ & $2.34 \pm 0.14$ & $2.53 \pm 0.07$ & $2.33 \pm 0.17$ & $2.57 \pm 0.09$ & $2.54 \pm 0.17$ & $2.93 \pm 0.13 \# *$ \\
\hline FS $(\%)$ & $41.5 \pm 1.93$ & $38.2 \pm 1.13$ & $42.3 \pm 2.15$ & $36.3 \pm 1.91$ & $38.9 \pm 2.19$ & $31.7 \pm 2.07 * *$ \\
\hline LVM (mg) & $107 \pm 4.53$ & $106 \pm 3.58$ & $105 \pm 2.30$ & $99 \pm 4.56$ & $103 \pm 4.74$ & $105 \pm 2.93$ \\
\hline
\end{tabular}




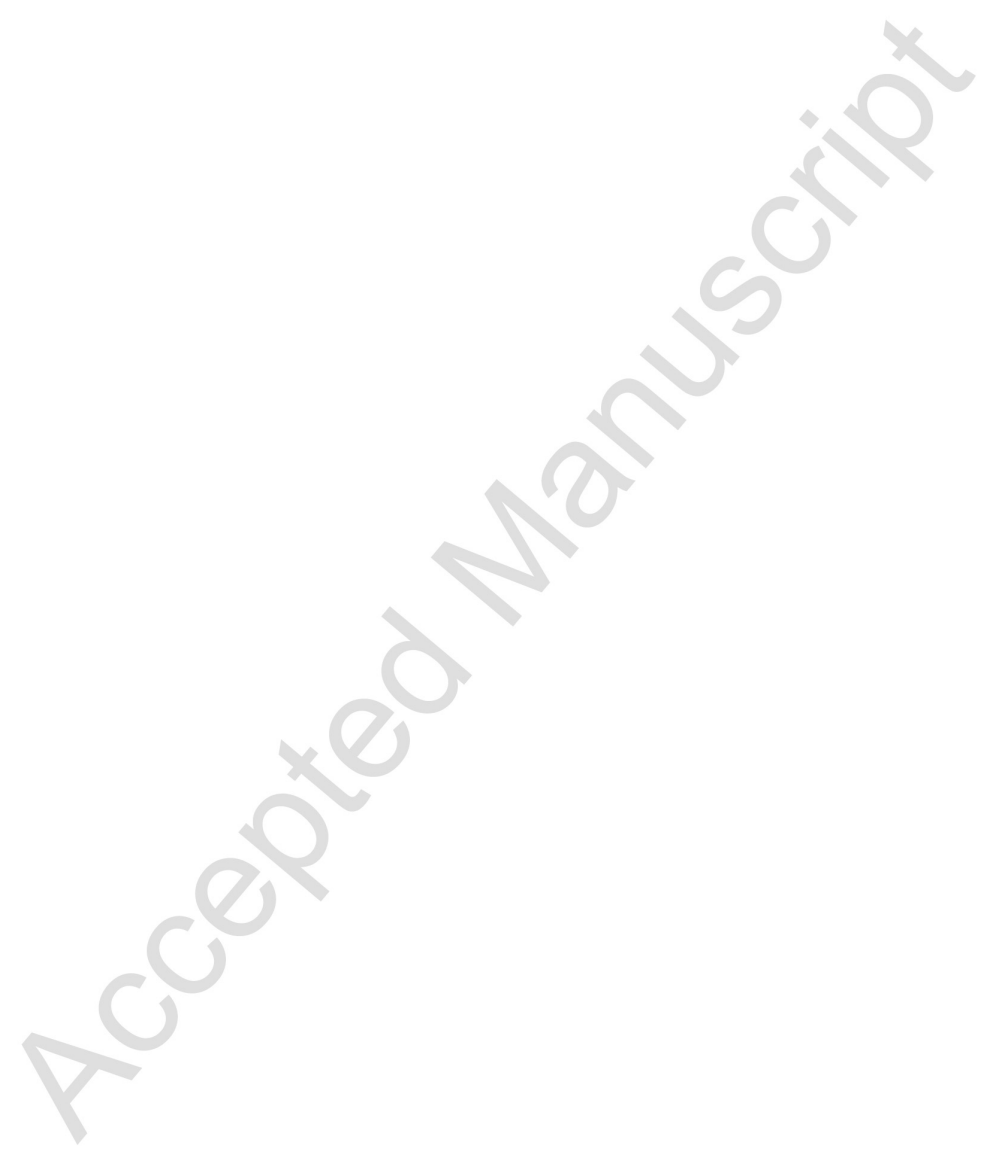

